\title{
Article \\ How Pedagogy 2.0 Can Foster Teacher Preparation and Community Building in Special Education
}

\author{
Elizabeth Hardman \\ School of Education, Northcentral University, San Diego, CA 92106, USA; E-Mail: ehardman@ncu.edu
}

Submitted: 31 July 2015 | In Revised Form: 23 November 2015 | Accepted: 17 December 2015 |

Published: 28 December 2015

\begin{abstract}
This paper describes how one teacher educator used action research methodology to investigate the feasibility of using Web 2.0 technology to build a virtual professional learning community (PLC) in special education to support the preparation of highly qualified special education teachers. Study participants included 218 pre-service and in-service teachers who joined the virtual PLC over a four-year period. Data were collected using two Web 2.0 tools, wiki and Ning, and analyzed to evaluate the degree to which the virtual community met the essential characteristics of a PLC. The results showed that 200 of the 218 graduate students who joined the PLC as graduate students continued their membership after graduation but participated in community work as observers only, rarely if ever contributing anything to community growth and development. The implication of the results are discussed with respect to the importance of preparing teachers for service in today's modern $21^{\text {st }}$ Century academically diverse, inclusive learning communities.
\end{abstract}

\section{Keywords}

pedagogy; professional learning communities; special education; teacher education; technology

\section{Issue}

This article is part of the special issue "Inclusive Technologies and Learning", edited by Don Passey (Department of Educational Research, Lancaster University, UK).

(C) 2015 by the author; licensee Cogitatio (Lisbon, Portugal). This article is licensed under a Creative Commons Attribution 4.0 International License (CC BY).

\section{How Pedagogy 2.0 Can Foster Teacher Preparation and Community Building in Special Education}

The mastery of pedagogy is of critical importance in the development of quality special education teachers (Blanton, Sindelar, \& Correa, 2006), but the pedagogy learned in pre-service preparation will not take root in practice without ample opportunities to engage in a wide variety of course related field experiences and induction support during the first few years of teaching (Kozleski, Mainzer, \& Deshler, 2000; National Council for the Accreditation of Teachers [NCATE], 2008). Field experiences and induction support play a vital role in the formation of quality teachers because both provide authentic opportunities to observe and practice what is known and being learned about the practice under the collaborative supervision and mentorship of teacher educators and experienced practitioners (e.g., Rosen- berg, O'Shea, \& O'Shea, 2006). When teachers with wide ranging levels of expertise engage in dialogue from inside the practice, the foundation is laid for the emergence of a professional learning community (PLC) that has the capacity to promote discovery and continuing professional growth for all involved (Billingsley, 2004). Work becomes the linchpin that connects research to practice.

The participation of teacher educators in schoolbased PLCs represents no small challenge for it requires them to step out of the safety of their own classrooms and into the realities of schooling (Bay \& Parker-Katz, 2009) where the veracity of theory and research will surely be questioned and tested ( $O$ 'Shea, Hammitte, Mainzer, \& Crutchfield, 2000). Moreover, many schools employ only a few special education teachers at best and sometimes just one or two, which means it may be necessary to build multiple partner- 
ships at widely scattered schools to satisfy students' field experience needs (e.g., Epanchin \& Colucci, 2002; Jenkins, Pateman, \& Black, 2002). This solution, however, is impractical in terms of time, travel, and institutional resources available for partnership building in the field (Conderman, Morin, \& Stephens, 2005) but may also explain why many special education personnel preparation programs are disconnected from the realities of schooling, lack an organized approach toward linking pedagogy with practice, and have produced little research on the benefits of field experiences and induction support (Billingsley, 2004; Boyer, 2005; Jones, 2009; Sindelar, Brownell, \& Billingsley, 2010). This paper reports the results of an action research project conducted to explore the feasibility of using Web 2.0 technology to design a virtual PLC to support the practice of special education and facilitate collaboration among teacher educators and aspiring, novice, and veteran special educators.

\section{The Challenges to Community Building Field Experience and Pre-Service Preparation}

Aspiring special educators cannot be adequately prepared for service without extensive opportunities to observe and practice with experienced general and special education teachers in a variety of educational settings that embrace the prevailing philosophy of inclusion (Blanton et al., 2006; Conderman et al., 2005; Epanchin \& Colucci, 2002; Jenkins et al., 2002; Klingner, Lefwich, van Garderen, \& Hernandez, 2004; NCATE, 2008). Some teacher education programs develop professional development schools to meet students' field experience needs (Klingner et al., 2004), but this approach does not offer the variety of experiences needed to be adequately prepared for service (Epanchin \& Colucci, 2002; Jenkins et al., 2002). Others programs provide an office of field experiences that assigns students to schools and employs clinical instructors to supervise fieldwork (Cochran-Smith et al., 2012). This model, however, can result in a lack of quality control because there is no assurance that the practices observed in the field will match the pedagogy taught during personnel preparation (Epanchin \& Colucci, 2002; Prater \& Sileo, 2002, 2004).

Prater and Sileo (2004) conducted research on the use of clinical instructors to oversee field experiences in special education. They found that the average rate of observation was once every 46.5 hours for course related fieldwork and once for every 70.3 hours for student teaching. These results suggest that most of the responsibility for field experience supervision falls upon cooperating teachers who may or may not be adequately prepared for the task. The results also revealed that only $3 \%$ of responding teacher education programs required cooperating teachers to participate in any kind of professional development prior to super- vision or to have more than one to three years of classroom experience. Thus, many aspiring special educators may be learning the practice from teachers who are not adequately prepared to serve as cooperating teachers and, as a result, may enter the field lacking the knowledge, practical experiences, and background needed to assume a competent practice (Bay \& ParkerKatz, 2009; Billingsley, 2004).

The best method for ensuring a good match between the pedagogy taught in pre-service education and that which is modeled in the field is for teacher educators to develop field sites and supervise their own course-related field experiences (Epanchin \& Colucci, 2002). This model is sometimes practiced with the help of a clinical experiences staff person and sometimes not (Prater \& Sileo, 2002, 2004). Since most schools employ only a few special education teachers at best and perhaps as many as half of those are either novices in their first few years of teaching or out-offield aspiring special educators (e.g., Boe \& Cook, 2006), it can be very difficult to find enough quality field sites to meet every student's needs (Epanchin \& Colucci, 2002; Jenkins et al., 2002). Moreover, research on teacher attrition in special education has consistently shown that the number of teaching vacancies that occur each year far outstrips the number of newly qualified graduates prepared to occupy those positions and that many of those who leave their classrooms each year are seasoned veterans (McLeskey \& Billingsley, 2008).

\section{Induction Support for Novice Special Educators}

The chronic shortage of experienced special educators also affects the availability of induction support for novices in their first few years of teaching. Smith and Ingersoll (2004) found that only about $1 \%$ of beginning teachers receive any kind of induction support and estimated that the turnover rate among those who do not receive induction support at about $41 \%$. Smith and Ingersoll also found that the largest reduction in turnover was associated with induction support that engaged novices into collaborative networks with more experienced peers. There is no doubt that isolation and a lack of access to professional development have an adverse affect on the retention of novice special educators (Kozleski et al., 2000), even those who are among the most competent graduates (Cochran-Smith et al., 2012; Jones, 2009; Smith \& Ingersoll, 2004). On the other hand, novice special educators have a much higher probability of becoming tomorrow's veteran teachers if given access to a comprehensive, welldesigned induction support program that engages them in collaborative networks with more experienced peers (Billingsley, 2004; Carr \& Evans, 2006; Little \& King, 2008). Yet, few programs have been developed that specifically address the induction of novice special educators into the profession (Boyer, 2005). 


\section{Developing a Collaborative Culture of Learning}

Teacher isolation and lack of access to quality professional development highlight the need for building supportive networks among special educators at every level of practice (Boe \& Cook, 2006), for it seems impossible to imagine how anyone can practice the pedagogy of inclusion and experience isolation at the same time (Hardman, 2012). Formal and informal networking breaks down isolation and facilitates continuing professional development by creating authentic forums for collaboratively thinking through problems with practice from inside the practice itself (Billingsley, 2004; McLeskey \& Waldron, 2000; Smith \& Ingersoll, 2004). Every special educator, pre-service to seasoned veteran, needs liberal access to (a) formal and informal networks of support (Smith \& Ingersoll, 2004) and (b) quality professional development that is tightly focused on mastering the evidence-based practices (EBPs) that are known to bring about the most significant and meaningful changes in student learning (Billingsley, 2004; Kozleski et al., 2000). Professional learning communities (PLCs) can provide both (McLeskey \& Waldron, 2000), but are difficult to realize in special education because the potential collaborators are usually distributed across multiple school sites (Hardman, 2012).

Special education is a student-centered practice that requires teachers to frame and re-frame their professional development needs as they critically reflect on their work and generate knowledge and beliefs about content, pedagogy, and the learning characteristics of the their students (Leko \& Brownell, 2009; McKenzi, 2009). They must be "active and resourceful in seeking to understand how language, culture, and familial backgrounds interact with exceptional conditions to impact an individual's academic and social abilities, attitudes, values, interests, and career options" across all content areas, ages, and ability levels (NCATE, 2008, p. 73). This means that they must be as skillful at collaboration as they are at teaching (Blanton et al., 2006; Conderman et al., 2005). They must also claim active membership in not one but two PLCs, one with their school-based general education colleagues and another with their discipline-based special education colleagues (Leko \& Brownell, 2009; McKenzi, 2009). Yet, the art of collaboration is difficult if not impossible to master in isolation or without access to quality professional development that is specifically designed to meet the needs of a student-centered practice (Billingsley, 2004; NCATE, 2008; Sindelar et al., 2010).

The challenges associated with community building in special education are only surface indicators of what appears to be a much larger problem; that is, isolation and limited access to quality professional development as teacher candidates matriculate through and exit their personnel preparation programs and assume their roles as teachers. Solutions may lie in easy to use and readily available Web 2.0 technology, a category of Internet tools that are particularly well suited for the purpose of community building (Hardman, 2012, 2014; Sindelar et al., 2010). Web 2.0 refers to the second generation of the Internet that differs from the original concept of the Internet as a one-way delivery of information by allowing users to move beyond passively absorbing whatever is posted on the Internet to actively participating in the creation of Web content (Schrum \& Levin, 2009).

It is also important to note that PLC development is not well researched or understood because PLCs tend to be school-based and develop informally (McLaughlin \& Talbert, 2006). Schlager and Fusco (2003) conducted a comprehensive review of the literature to identify the essential characteristics of PLCs but also described how each one might be enhanced using Web 2.0 technology to support community building. Given that Web 2.0 is made up of a collection of empty databases until individuals interact with them, its capacity for data collection presents new possibilities for research on PLC growth and development (Hardman, 2011, 2012). Thus, the purpose of the present study was to use Web 2.0 technology to design a virtual PLC and to observe its growth and development using action research methodology to analyze data collected from the community's websites. More specifically, data were collected and analyzed to address the following question: Can Web 2.0 technology be used to design a Web-based PLC that engages teacher educators and aspiring, novice, and veteran special educators in a collaborative effort to provide quality field experiences, induction support, and continuing professional development in the practice of special education?

\section{Method}

Action research is a type of applied research conducted for the purpose of finding solutions to problems teachers meet within their own practice (Dane, 2011; Leedy \& Ormrod, 2016). It typically originates with an idea or a specific focus of interest and empowers practitioners as problem solvers by providing timely, targeted, pragmatic research procedures (Krathwohl, 2009) for improving the overall quality, impact, and rationality of the practice (Gall, Gall, \& Borg, 2007). Problems related to practice are usually complex problems that cannot be resolved with a single action but require a succession of strategies that are implemented over time (Krathwohl, 2009). Action research is well suited for that purpose because it is self-reflective and cyclical in nature. Once the problem is identified, an implementation plan is developed. Data are then collected and analyzed through successive cycles of reflection, action, and evaluation with each cycle providing a better understanding of the problem as modifications are made to the implementation plan as indicated by the analysis (Gall et al., 2007). 


\section{Setting and Participants}

This action research project was conducted at a moderately sized, private university (approximately 25,000 students) located in a large Midwestern metropolitan area. Approximately 1,500 graduate and undergraduate students were enrolled in the University's School of Education, working toward degrees in early childhood education, elementary and secondary education, physical education, bilingual/bicultural education, reading, and special education. Student teaching internships were managed through the Office of Field Experiences and Student Teaching and no formal induction support was offered beyond graduation. Placement assistance for field experiences was provided upon request but in most cases, it was the student's responsibility to find a field site where the cooperating teacher had a minimum of three years experience and was certified in the field in which he or she was teaching.

The idea for the study emerged when a teacher educator in special education attempted to integrate professional development in the Strategic Instruction Model (SIM, University of Kansas Center for Research on Learning, UK-CRL, n.d.) into her special education graduate level coursework. Neither she nor her students were able to find sufficient numbers of cooperating teachers who knew the model at all or well enough to supervise fieldwork. This prompted the teacher educator and a few of her graduate level pre-service educators to form the Strategic Instruction Network (SIN) for the purpose of developing a network of alumni who had begun their professional development in SIM as students and wished to continue after graduation by supervising fieldwork. Anticipating the many problems associated with delivering professional development at multiple schools simultaneously, the teacher educator solicited advice from a technology consultant in designing a virtual PLC using a wiki (www.pbworks.com) to provide a repository for professional development content and a Ning (www.ning.com) to support social networking.

Over the next four years, 116 pre-service elementary/special educators, 77 in-service special education teachers, and 25 general educators enrolled in the teacher educator's special education graduate level methods courses joined the SIN-PLC $(\mathrm{N}=218)$. Table 1 details the number of student participants who joined SIN by year and program of study. The pre-service educators were required to complete 15 field experience hours per course and the in-service teachers 10 hours per course. The in-service teachers could also complete their fieldwork assignments at their schools but this option that was not available to the pre-service teacher candidates. The pre-service program was developed for career changers pursuing dual certification in special and elementary education. Finding field sites was more difficult for this group because they were not teachers and had few or no school contacts. They were also sometimes enrolled in as many as three methods course during a quarter term, meaning that they were required to complete a total of 45 field experience hours in a short 10 week time period.

\section{Data Collection and Analysis}

Similar to school-based PLCs, the SIN-PLC was envisioned to be a democratically managed community that placed almost total control for community growth and development in the hands of its membership using Web 2.0 software to encourage communication, collaboration, experimentation, and innovation (Hardman, 2012). Action research typically employs the use of data collection procedures that are simple and unobtrusive in order to minimize interruptions to the practice (Krathwohl, 2009). Wiki (www.pbworks.com) and Ning (www.ning.com) provided the basic infrastructure for the virtual PLC but also supplied the data sources through which community development could be unobtrusively observed. Observing and describing community development also requires a framework to guide data collection and analysis. Schlager and Fusco's essential characteristics of community development (2003) provided the framework that guided data collection and analysis. The eight essential characteristic of community development are identified and briefly defined along with the corresponding data source(s) for each one as the results of the analysis are described below.

\section{Results}

\subsection{The Practice}

The practice lies at the heart of community work. Virtual PLCs use technology to support the engagement of every community member in the practice as opposed to addressing the individual roles of each member in isolation (Schlager \& Fusco, 2003). The SIN-PLC was initiated

Table 1. Number of student participants by program and year.

\begin{tabular}{llllll}
\hline Program & Year 1 & Year 2 & Year 3 & Year 4 & Total \\
& $\mathbf{2 0 0 8 / 0 9}$ & $\mathbf{2 0 0 9 / 1 0}$ & $\mathbf{2 0 1 0 / 1 1}$ & $\mathbf{2 0 1 1 / 2 0 1 2}$ & \\
\hline Pre-Service (Elementary/Special Education Teachers) & 30 & 25 & 30 & 31 & 116 \\
In-Service (Special Education Teachers) & & 24 & 33 & 20 & 77 \\
In-Service (General Education Teachers) & & 15 & 0 & 10 & 25 \\
Total & 30 & 64 & 63 & 61 & 218 \\
\hline
\end{tabular}


for the purpose of providing professional development in SIM's Learning Strategies Curriculum and Content Enhancement Routines (UK-CRL). Learning strategies define a set of skills students learn and use to acquire information from the printed word, organize and memorize information, solve math problems, express information in writing, and develop community building social skills. Content enhancement routines are instruction focused and direct teachers in ways to adapt and present critical content in a "learner-friendly" format to help students identify, organize, comprehend, and recall important information.

The SIN-Wiki provided a collaboratively built repository for professional development content in SIM (UKCRL). The FrontPage of the wiki featured a Navigator bar down the right side of the page that worked like a table of contents and included folders for the Content Enhancement Routines and Learning Strategies learned in class. The Navigator bar also included Sandbox folders to provide a space where groups could collaboratively develop multimedia projects to share with the membership upon completion. Quick links located above the Navigator bar allowed users to create new folders or pages as needed, upload files they wished to link to existing pages, access their account information, or contact help. An editable SideBar was located below the Navigator with links to the PBworks User Manual, a Wiki Tutorial, and the SIN-Ning (Hardman, 2011, 2012, 2014).

The file upload page facilitated the organization and management of the wiki pages and folders and recorded the file name, format, and the date the file or page was last changed. As users interacted with the professional development content, the wiki's versioning capability created page histories that recorded any changes made to a page, the person who made the change, a description of the change, and the time and date the change was made. Users could also edit pages and revert to an earlier version if they wished. Wiki software also created Adobe formatted files of documents and pages that could be downloaded for personal use by anyone in the community. The teacher educator served as the wiki administrator and had access to a list of users that included a photograph, the date of the user's first and last visited to the wiki, the user's email address, and page view count (see Hardman, 2011, 2012, 2014, for a more detailed description of the SIN-Wiki).

The SIN-Ning provided a private social networking website. The Main Page included information about the purpose of the network, how to get started, a list of members and special interest groups, upcoming events, and a link to the SIN-Wiki. Each member was given a My Page when the account was created that could be personalized by selecting a theme and appearance from a wide variety of choices. Tabs located at the top of every page facilitated the website navigation and included tabs for the Main Page, Invite, My Page, Members, Forums, Events, Groups, Chat, and Videos. Users could also communicate with others within the community using their SIN-Ning email or by creating or contributing to a discussion on one of the special interest group pages. In addition, users could post upcoming events, initiate special interest groups, upload or link professional development content, share links to other websites, or blog about their professional growth and teaching experiences. The website also offered a directory of over $100 \mathrm{Apps}$ that could be added to My Page as needed to enhance communication, productivity, collaboration, and knowledge generation (see Hardman, 2011, 2012, 2014, for a more detailed description of the SIN-Ning).

The original project implementation plan included a technology consultant to provide training and support for the teacher educator and her students, but the technology consultant became ill during the planning stage and was unable to continue. This left the teacher educator, who had no experience in website development, to design and administer both websites with little support from technology. Since neither website required expertise in website building to develop, this seemingly unfortunate turn of events proved to be asset rather than a liability because it allowed expertise in technology to emerge from within the community (Hardman, in press). When technology experts assume total responsibility for managing a virtual PLC, the membership tends to rely on those consultants to resolve any and all technology related problems (Farooq, Schank, Harris, Fusco, \& Schlager, 2007). This creates an overwhelming burden for the few who assume total responsibility for the management of the community websites but more importantly, defeats the purpose of developing a democratically managed PLC (Hardman, in press).

\subsection{Social Networks}

Formal and informal social networks lay the foundation upon which PLCs are built (Schlager \& Fusco, 2003). Ning software facilitated networking by allowing the membership to build smaller networks within the PLC by friending others, creating or joining special interest groups, or initiating and participating in forums and discussions within the community at large or special interest groups. The Really Simple Syndication (RSS) feeds supported networking by notifying each member via email when a comment was made on the member's My Page, a discussion post was made on the member's group page, or an event was posted be anyone in the community. The teacher educator modeled how the special interest groups could be used to enhance social networking by creating group pages for each of the strategies and teaching routines presented in face-toface workshops during class. For each group created, she also initiated the first discussion and invited students to respond to that discussion or to initiate other discussions about the practice as needed (Hardman, 2012).

Table 2 lists the special interest groups that were 
created along with the date the professional development content was delivered and the date each group was last visited. These results show that the number of members who joined a group ( $\mathrm{N}=112)$ was far less than the number of SIN-Ning users at the time the data were collected $(\mathrm{N}=156)$. It is also important to note that the number of group participants does not represent discrete units of measurement in that some of the members joined more than one group. The groups with the most members were learning strategies that were to be implemented at a field site and those with the least members had no fieldwork requirement. The teacher educator created all of the groups as professional development content was delivered in class with one exception. A high school English teacher created the Possible Selves (UK-CRL) group to facilitate fieldwork at his school. His group was the most active of all the groups and his My Page accumulated the greatest number of friends with a total of 24 . A few of the graduate students had 5 to 10 friends, but the majority had only 2 or less and rarely if ever made any comments on friends' pages, including the English teacher's My Page (Hardman, 2012).

\subsection{Learning Processes}

PLCs promote learning as a social activity that occurs in the context of work. New and less skilled members are inducted into the profession through dialogue about practice with more experienced colleagues (Schlager \& Fusco, 2003). The SIN-Wiki provided the software needed to engage the membership in collaboratively tailoring the professional development content presented in class to meet their specific instructional needs as well as the needs of the community at large. For example, a student implementing one of the sentence writing strategies in a fifth grade inclusive general education classroom might modify and use the profes- sional development content differently than would a student implementing the same strategy in a ninth grade special education resource room. All of the graduate students were assigned writer status when they created a wiki account, which granted access to the wiki's Edit tab. The Edit tab transformed the wiki into a group managed multimedia composition system that allowed users to edit pages, create pages, and upload a variety of content including documents, images, slides shows, and videos. RSS feeds further enhanced the wiki's collaborative functionality by notifying users via email when changes were made to any part of the wiki, summarizing the changes made, providing the date and time they were made, and identifying the person who made them.

The teacher educator prepared the graduate students to collaboratively engage in the creation and design of group projects by making small group assignments that were to be completed in the wiki's Sandbox folder. For example, after learning how to create class wide and individualized behavior management plans in class, small groups of four were then assigned to use what they had learned to develop behavior management plans on the SIN-Wiki. Each group was required to create a group folder in the wiki Sandbox and to use it to develop the plan asynchronously over a threeweek period. Detailed instructions were provided on the wiki about what the plan was to include, but no class time was provided to work on the project face to face. Before beginning any work on the behavior management plan, the group was instructed to develop a team charter using the form depicted in Figure 1. They were to post the charter in the group folder and each group member was required to contribute at least five substantive revisions to or comments about the project to ensure that everyone participated in the development of the project.

Table 2. SIN-Ning groups by date last visited and number of members.

\begin{tabular}{llll}
\hline Group Name & Date Content Presented & Date Last Visited (m-d-y) & Number of Members \\
\hline Question Exploration Routine & $5-11$ & $5-13-11$ & 1 \\
Concept Mastery & $5-11$ & $5-13-11$ & 1 \\
Classroom Management & $2-11$ & $2-20-11$ & 3 \\
Organizing Together & $2-11$ & $2-3-11$ & 1 \\
Course Organizer & $2-11$ & $2-3-11$ & 2 \\
Unit Organizer & $2-11$ & $8-14-11$ & 1 \\
Possible Selves & $1-11$ & $3-2-11$ & 34 \\
SCORE & $1-11$ & $2-16-11$ & 12 \\
Fundamentals in Sentence Writing & $9-10$ & $2-14-11$ & 24 \\
Proficiency in Sentence Writing & $9-10$ & $2-14-11$ & 16 \\
Word ID & $9-09$ & $10-14-09$ & 17 \\
Total & & 112 \\
\hline
\end{tabular}

Note: some may be members of more than one group and the PI is a member of every group. Adapted from Hardman (2012). Copyright by the Journal of Special Education Technology. 


\begin{tabular}{lr}
\hline & $\begin{array}{r}\text { Team Charter } \\
\text { Group Name }\end{array}$ \\
\hline Team & (list names and contact information) \\
Timeline & $\bullet$ Kickoff: (start date)
\end{tabular}

Timeline

- Kickoff: (start date)

- Project Manager Assigns Tasks/Milestones and Due Dates:

- Project Due Date:

- Celebration:

Team Charter $\quad \bullet$ Team Member Skill Inventory

(Areas individual members can contribute/want to develop. Assign a role for each group member and define the duties associated with the assigned role. One person should be assigned the role of Project Manager.)

- Learning Team Goals

(May include project assignment goals, group process goals, quality level goals, etc.)

\section{- Ground Rules}

(Meeting schedule, locations, attendance expectations, agenda, assignment completion, communication methods, etc.)

\section{Tasks/Milestones for} Project Completion
(Describe how the assignment will be completed by the due date. List each task the person responsible, and the date by which the task should be completed)

Figure 1. Team charter.

Upon completion of the project, the team charters, page histories, page comments, and the project itself provided data sources for assessing the role each group member played in contributing to the team effort as well as what the students learned about creating behavior management plan. RSS feeds also allowed the teacher educator to view the project as it was developed and redirect the team effort as problems and misunderstandings emerged. For example, when the groups were assigned to create a class wide behavior management plan, the team charters indicated that two groups were proposing the use of a jigsaw approach. This meant that each group member would complete a part of the project (class description, rules, reinforcement plan, and monitoring system) in isolation without consultation from any of the other group members. A group technology expert would then collect and upload each part to form the whole when it was due. RSS feeds allowed the teacher educator to intervene in the execution of this faulty plan and redirect the group into using a more collaborative approach that involved everyone in all parts of project development.

\subsection{Community Reproduction and Evolution}

PLCs give voice to every community member in select- ing and designing their own learning experiences as the community grows, evolves, and reproduces its membership (Schlager \& Fusco, 2003). The SIN-PLC promoted this democratic model of professional development by giving equal voice to everyone in selecting and designing professional development content to meet individual needs. Members could develop or choose to participate in a special interest group on the Ning, share or select professional development events to attend from the Events calendar, develop or select professional development content archived on the wiki or Ning My Pages, and much more using the wide variety of over 100 Apps available on the Ning, such as file sharing apps, blogging apps, communication apps, Facebook, Linkedin, Delicious, YouTube, Vimeo. For example, the membership used the YouTube and Vimeo apps to publish group produced teaching videos that were videotaped during class and shared on the SIN-Ning.

Over the course of time, the teacher educator posted a total of 10 events to announce state and national level professional development conferences and provided registration information with the event posting. Since there was little or no response to these Event postings at first, she began using the Network Broadcast function to boost event postings with a network wide email. As a result, 26 SIN-Ning users attended the 
broadcasted event, 19 of whom were current students who earned bonus points for attending but 6 were program alumni and one was a former student who had not yet graduated from the program. The high school English teacher also used the Events calendar to promote a field experience orientation meeting to be held at his school for interested pre-service educators. The event was well attended by 15 students who wanted to experience teaching in an inner city, alternative high school for students at high risk for drop out.

The SIN-Wiki recorded a profile on every user that recorded the number of page views per user and the first and last date the user entered the wiki. The page number views are presented in Figure 2 and show that a majority of the wiki users viewed the pages and files created on the wiki between 0 to 10 times $(n=87)$ over a short period of time that coincided with the dates at which the professional development content was presented in class and assignments were made to be completed on the wiki. Even though the data also show that 77 participants viewed the pages at a much greater rate (11-200 times), most of those page views also occurred as a result of course assignments. Data collected on the first and last visit to the SIN Wiki showed that only 24 of the 218 users revisited the wiki after the course was completed but prior to graduation, presumably to retrieve artifacts created during the course to include in their professional portfolios, submit with job applications, or reuse in their own classrooms. In one case, a graduate student in the special education for teachers program reported to the teacher educator that she implemented a science lesson plan in her first grade classroom that was prepared by a group of preservice graduate students and posted on the SIN-Wiki as a group project.

\subsection{History and Culture}

PLCs develop and continually reproduce their cultural artifacts, norms, and values over time (Schlager \& Fusco, 2003). Supporting the induction of new members into the history and culture of the practice from within the community was of particular importance in preparing the pre-service graduate students for practice and provided the impetus for the developing the project in the beginning. In fact, it was in collaboration with a group of pre-service educators that the idea for the project originated. They were the ones who stood to gain the most from the project because they had no experience teaching and had few or no inside connections to schools. The in-service and pre-service graduate students were enrolled in the same methods courses, but they were in different sections of those courses, which made arranging mentoring opportunities between the two groups difficult. The SIN-PLC filled that need by creating a virtual space where the two groups of teachers, in-service and pre-service, could meet and work collaboratively in the production and reproduction of the community's artifacts, norms, and values.

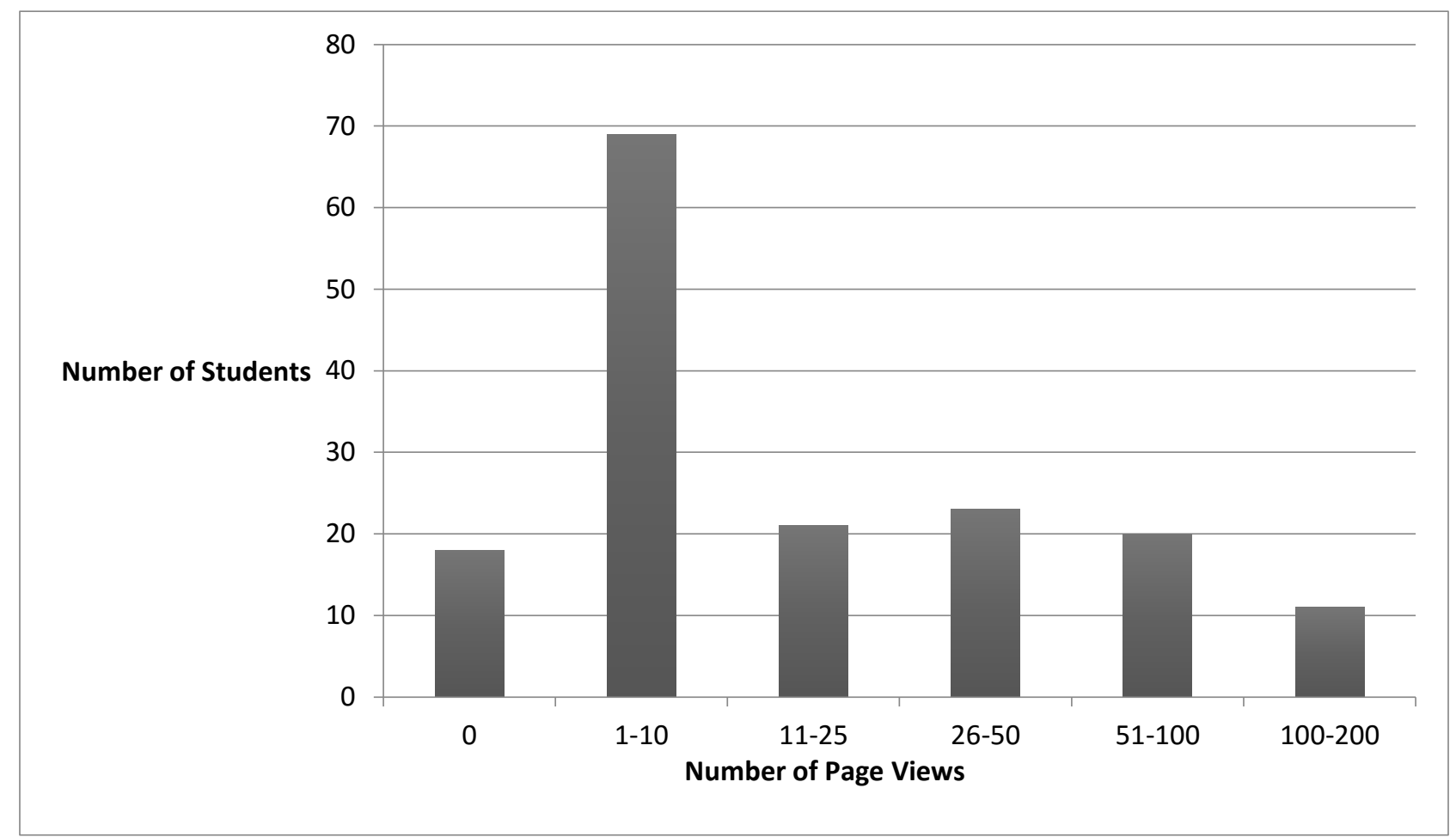

Figure 2. Number of page views per student. Note: these data were collected two years after the project ended at which time there were only 169 of the 198 program alumni who remained members of the SIN-PLC. 
Since the involvement of the high school English teacher resulted in increased level of social networking (see Table 2, Possible Selves), the teacher educator created a Making Connections discussion board within one of the SIN-Ning special interest groups. She then required her 29 pre-service educators and 10 general education teachers enrolled in an online special education endorsement program to join the group and use the discussion board to introduce themselves to the group, describe their classrooms if they were teachers or their teaching interests if they were pre-service educators, and to post their contact information if they were looking for or could provide a field site at which to implement a strategy or routine. This assignment was followed up with a Message Broadcast to all SIN-Ning users inviting them to visit the group discussion board and consider supervising fieldwork for one or more pre-service educators. Within a two-week time period, all of the 29 pre-service educators were able to secure a field placement, with a vast majority finding a cooperating teacher through the SIN-Ning (Hardman, 2012).

\subsection{Tools, Artifacts, and Places}

Communication, productivity, collaboration, and knowledge generation depend on the production, reuse, and refinement of community's tools, artifacts, and places (Schlager \& Fusco, 2003). As the community interacted with the professional development content, the practice, and each other, the SIN websites offered a variety of Web tools and a great deal of versatility with respect to the production, reuse and refinement of community artifacts. As the teacher educator presented professional development content in class, she made assignments that were to be completed on the SIN-Wiki and Ning to familiarize the community with the ways in which wiki and Ning might be used to collaboratively engage in the creation of professional development content to share with others in the community.

As a result of this effort, the teacher educator and her students created 607 files and 206 pages of professional development content on the SIN-Wiki and developed 44 teaching demonstration videos and 131 reflection blogs to share with the community on the SINNing. Yet data collected from the wiki databases showed that no one returned to the wiki after the completion of course assignments to produce or refine artifacts. Moreover, data collected on the first and last visit to the SIN-Wiki and additions to members' SINNing My Pages showed that no one produced, edited, shared or reused anything on either website after graduation or used either website to facilitate collaboration, communication, or professional networking.

\subsection{Leaders and Contributors}

A central aspect of community development is the emergence of leaders and contributors from within the community (Schlager \& Fusco, 2003). In a democratically managed, virtual PLC, every member must also be equipped with the technical capabilities needed to take on a leadership role when needed and make meaningful contributions to community development. Leaders and contributors are needed to (a) identify important issues upon which to focus community work; (b) plan and facilitate community events; (c) link with others in the community and promote communication among members who have similar interests; and (d) negotiate the boundaries between the community and the school by ensuring community access to necessary resources (McLaughlin \& Talbert, 2006).

Barab, Makinster, and Scheckler (2003) identified four levels of membership in virtual PLCs; observers who visit the site but do not contribute content or participate in online discussions, active members who engage in discussions but do not contribute professional development content, contributing members who pose questions for discussion on community forums and share content in the form of videos and other artifacts associated with teaching, and bounded group members who join the PLC as a part of a collective experience such as a teacher education class, professional development workshop, or similar experiences.

The majority of the SIN-PLC membership joined as bonded group members during graduate school and were pre-service teachers $(n=116)$ seeking an initial licensure in elementary and special education. The remaining members were in-service special $(n=77)$ and general educators $(n=25)$ and were already a part of the school community to varying degrees of involvement. In the beginning, the teacher educator who initiated the project expected to assume sole responsibility for leading the community and contributing most of the professional development content, but she also used the community websites as tools to prepare the membership with the technical capabilities needed to become actively engaged leaders and contributors in a virtual PLC (Hardman, 2012). In spite of those efforts, data collected from both websites indicated that a majority of the SIN-PLC membership participated in community work as observers only. They did not produce any professional development content on the wiki or comment on any of the content developed unless they were directed to do so. They also did not use the SINNing to share any of the artifacts or projects they developed on the wiki, create or respond to any discussion posts unless assigned, or volunteer to comment on contributions made by others (Hardman, 2012).

\subsection{Membership Identity and Multiplicity}

As leaders and contributors emerge from within the community, membership identity and multiplicity evolves over time as the membership uses technology 
to build and manage their professional identities, find and collaborate with others according to their similar interests, and function in multiple roles from beginner to accomplished practitioner (Schlager \& Fusco, 2003). Since the SIN-PLC began with only 30 pre-service teacher candidates, membership identity and multiplicity was a primary focus in the first few years of development (Hardman, 2012). The SIN-Ning My Page provided the venue for developing a professional identity, finding and building collaborative relationships with others, and functioning in multiple roles from beginner to accomplished practitioner. Ning users began the process of developing a professional identity when they joined the network by posting a profile on My Page that included the following information; current teaching status (in-service or pre-service teacher, general or special educator), contact information, grades taught or grades interested in teaching, number of years teaching, and the strategies or routines known and those they wished to learn.

Over the next four years, 218 pre-service and inservice special and general educators joined the network and all but 20 continued after graduation. The membership was increasing rapidly; however, most of them were novices with only one to three years of teaching experience at best. Nevertheless, it was expected that program graduates would update their My Page profiles and share their accomplishments as they completed their graduate studies and moved out into the field to begin their careers as teachers. Data collected from the SIN-Ning indicated that this did not happen. In reality, no one updated My Page after first joining the network, which made it difficult to determine what any of the participants had accomplished since graduation or who was teaching and where and who was not (Hardman, 2012).

\subsection{Preparing Special Educators to Lead 21st Century Learning Communities}

This study was conducted to develop a virtual professional learning community (PLC) to provide quality field experiences, induction support, and continuing professional development in the practice of special education. Successes were realized in the creation of a network of alumni to support the provision of field experiences for pre-service educators, but the capacity of the network to provide induction support and continuing professional development was still evolving when the project was terminated four years after it began. The results showed that over the course of the four-year project, the community grew in numbers, from 30 pre-service graduate students to 218 , with only 20 students choosing not to continue beyond graduation. Numbers, however, do not tell the whole story.

Both PLCs and Web 2.0 technology require an understanding of teaching and learning as a highly active, socially engaging endeavor. It is a simple formula for effectiveness. One has to do something in order to get something. It became clear early on in the project that a majority of the membership was not favorably disposed toward actively engaging in their own learning or willing to do anything beyond meeting the course requirements as assigned by the instructor. It was as if they viewed teaching and learning much like the original concept of the Internet, a one-way street defined by passive consumption. The results of this study indicate that, for the most part, the membership either did not know how or did not see the importance of becoming active contributors, leaders, and collaborators in creating knowledge and building the community's collective knowledge base.

This outcome was concerning indeed, because we know that passive engagement in one's own professional development will not produce the level of pedagogical expertise required to address the widely varying instructional needs of students with disabilities across all subject areas, disability categories, grade and ability levels, and educational settings (Hardman, 2012, in press). Of even greater concern is what a passive approach toward learning may say about how teachers will view their own students as learners (Hardman, 2012, 2014). To maximize student achievement in an inclusive, academically diverse classroom, the classroom itself must function as a community of learners that is designed to promote the active engagement of every student in experiencing the joy of learning.

The fact that so many of the graduate students remained a part of the community beyond graduation indicates that perhaps they wanted to be a part of a professional learning community or they would have cancelled their memberships upon completion of the course. The more likely explanation for their collective lack of engagement in community work may be attributed to little or no experience learning in the context of community. When community wide broadcasts were used to invite the membership to professional development events and recruit in-service teachers to supervise fieldwork, the membership responded to the call. These results provided evidence of a willingness among program alumni to engage at a deeper level of involvement in community work when they are presented with a variety of ways in which to participate. For example, program alumni could be invited to serve as advisors to student groups in the completion of course-related assignments, help students produce teaching demonstration videos, comment on student blogs about their teaching experiences, participate in online discussions, present at in addition to attending professional development conferences, or serve as an editor, administrator, or technology consultant on the community websites.

The results also indicate that unfamiliarity with emerging technologies as well as a general unwilling- 
ness to experiment with or learn how to use technology to support teaching and learning also contributed to the community's preference for passive as opposed to active engagement in community work. This was a paradoxical outcome indeed, given that the very idea that was intended to facilitate community development may have played a significant role in limiting it (Hardman, 2012, 2014). Nevertheless, it is unrealistic in this day and age to expect teachers to embark upon a journey of lifelong learning, or to lead their students down that path with them, unaided by technology. Knowing how to use technology to support teaching and learning is no longer optional as it once was. It is mandatory (Hardman, in press).

The use of technology to support teaching and learning in today's academically diverse inclusive classrooms is widespread. Technology has always played an important role in the education of students with disabilities. Recent research provides abundant evidence that technology is and will continue to play a more prominent role in $21^{\text {st }}$ Century inclusive classrooms (Hardman, in press). For example, special educators are using Web 2.0 to differentiate instruction in mathematics (Bouck \& Meyer, 2012), writing (Jones, 2012; Olthouse \& Miller, 2012), and to create video models to teach the generalization of new skills (Carnahan, Basham, Christman, \& Hollingshead, 2012). They use wikis, blogs, vlogs, and social networks to support group planning and collaboration (Charles \& Dickens, 2012); Web-based software to design and conduct curriculum based assessment and to manage data collection and analysis (Goo, Watt, Park, \& Hosp, 2012); and Webquests, gaming, cloud computing, Apps, and the flipped classroom to enhance the differentiation of instruction (Bender, 2012).

It is also important to note that most if not all of the graduate students who participated in this project as well as the teacher education who conceived it were digital immigrants who remember a time when there was no Internet or personal computers, but that is not the case with the students they will teach (Schrum \& Levin, 2009). Today's students are tech savvy digital natives who have never known life without Internet, cell phones, video games, on-demand videos, portable computing devices; gaming, and Apps to fit every need. They are socially engaged, tuned-in, powered-up, and purposefully adept at customizing media to suit their learning needs. They are also young, inexperienced, and lacking in the judgment needed to responsibly assume their roles as $21^{\text {st }}$ Century digital citizens (Hardman, 2012). They will need tech savvy teachers to nurture and guide their development.

Technology is now and will continue in the future to transform teaching and learning in ways that have not yet been imagined (Bender; 2012; Ludlow, 2012; Schrum \& Levin, 2009). The vast amount of technology available is daunting and the learning curve will be steep for many of us. Nevertheless, we must embrace these modern technologies in order to prepare teachers to become leaders and contributors in today's classrooms. Unfortunately, many of today's schools, including schools of education, restrict or prohibit access to the Internet, social media, or the use of mobile computing devices when instead, these innovative tools for learning should become an integral part of instruction. For example, the SIN-PLC was terminated after four years because the revenues generated by enrollment dropped. Technology initiatives were among the first to be eliminated from the budget. Schools of education cannot prepare teachers for service in the $21^{\text {st }}$ Century learning communities if technology is perceived as a luxury as opposed to a necessity (Hardman, in press).

The transformation of passive observers into active participants in a vibrant community of learners begins with a radical change in how we prepare teachers for service (Hardman, in press). The International Society for Technology in Education (ISTE, 2007, 2008) has developed National Educational Technology Standards for Teachers (NETS-T, 2008) and Students (NETS-S, 2007) as a guide for the integration of technology into teaching and learning. Table 3 shows how the two sets of standards are aligned in a way that prepares teachers to learn about, model and apply technology in the design, implementation, and assessment of their students' learning experiences. For example, the Teaching, Learning, and the Curriculum standard requires teachers to know how to "implement curriculum plans that include methods and strategies for applying technology to maximize student learning" is aligned with the student standard for Creativity and Innovation requiring students to, "demonstrate creative thinking, construct knowledge, and develop innovative products and processes using technology."

Teaching and learning are and will continue to be social activities that occur in the context of community. Therefore, it seems unrealistic to expect teachers to understand the importance of community building in their own classrooms if they are not also actively participating in a learning community to nourish their own professional development needs (Grossman, Wineburg, \& Woolworth, 2001). It would also be unrealistic to expect teachers to embark upon a journey of active engagement in lifelong learning unaided by technology. Web-based PLCs may not only provide a solution to the isolation and lack of access to continuing professional development common to the practice of special education but may also provide an authentic training ground for preparing teachers to become active participants in their own learning and transformational leaders in today's modern $21^{\text {st }}$ Century academically diverse, inclusive classrooms (Hardman, in press). 
Table 3. Comparison of ISTE NETS-T and NETS-S.

Teachers
implement curriculum plans that include methods and
strategies for applying technology to maximize student
learning
Engage in Professional Growth and Leadership:
Teachers continuously improve their professional
practice, model lifelong learning, and exhibit leadership
in their school and professional community by
promoting and demonstrating the effective use of
digital tools and resources.
Assessment and Evaluation: Teachers apply technology
to facilitate a variety of effective assessment and
evaluation strategies.
Technology Operations and Concepts: Teachers
demonstrate a sound understanding of technology
operations and concepts.
Productivity and Professional Practice: Teachers use
technology to enhance their productivity and
professional practice.

Social, Ethical, Legal, and Human Issues: Teachers understand the social, ethical, legal, and human issues surrounding the use of technology in PK-12 schools and apply that understanding in practice.
Students

Creativity and Innovation: Students demonstrate creative thinking, construct knowledge, and develop innovative products and processes using technology.

Communication and Collaboration: Students use digital media and environments to communicate and work collaboratively, including at a distance, to support individual learning and contribute to the learning of others.

Research and Information Fluency:Students apply digital tools to gather, evaluate, and use information. Technology Operations and Concepts--Students demonstrate a sound understanding of technology concepts, systems, and operations.

\section{Critical Thinking, Problem Solving, and Decision}

Making: Students use critical thinking skills to plan and conduct research, manage projects, solve problems, and make informed decisions using appropriate digital tools and resources.

Digital Citizenship: Students understand human, cultural, and societal issues related to technology and practice legal and ethical behavior.

Note: Reprinted from Hardman (in press). Copyright by IGI Global.

\section{Conflict of Interests}

The author declares no conflict of interests.

\section{References}

Barab, S. A., MaKinster, J. G., \& Scheckler, R. (2003). Designing system dualities: Characterizing a Websupported professional development community. The Information Society, 19, 237-256.

Bay, M., \& Parker-Katz, M. (2009). Perspectives on induction of beginning special educators. Research summary, key program features, and the state of state-level policies. Teacher Education and Special Education, 32, 17-32.

Bender, W. N. (2012). Differentiating instruction for students with learning disabilities. New best practices for general and special educators. Thousand Oaks, CA: Corwin.

Billingsley, B. S. (2004). Promoting teacher quality and retention in special education. Journal of Learning Disabilities, 37, 370-376.

Blanton, L. P., Sindelar, P. T., \& Correa, V. I. (2006). Models and measures of beginning teacher quality. The Journal of Special Education, 40, 115-117.

Boe, E. E., \& Cook, L. H. (2006). The chronic and increasing shortage of fully certified teachers in special and general education. Exceptional Children, 72, 443-460.
Bouck, E., \& Meyer, N. K., (2012). E-Text, mathematics, and students with visual impairments. What teachers need to know. Teaching Exceptional Children, 45(2), 42-49.

Boyer, L. (2005). Supporting the induction of special educators. Program descriptions of university school district partnerships. Teaching Exceptional Children, 37(3), 44-51.

Carnahan, C. R., Basham, J. D., Christman, J., \& Hollingshead, A. (2012). Teaching Exceptional Children, 45(2), 50-59.

Carr, S. C., \& Evans, E. D. (2006). Helping beginning teachers remain in the profession: A successful induction program. Teacher Education and Special Education, 29, 113-115.

Charles, K. J., \& Dickens, V. (2012). Closing the communication gap. Web 2.0 tools for enhanced planning and collaboration. Teaching Exceptional Children, 45(2), 24-32.

Cochran-Smith, M., McQuillan, P., Mitchell, K., Terrell, D.G., Barnatt, J., D'Souza, L.,..., \& Gleeson, A. M. (2012). A longitudinal study of teaching practice and early career decisions. A cautionary tale. American Educational Research Journal, 49, 844-880.

Conderman, G., Morin, J., \& Stephens, J. T. (2005). Special education student teaching practices. Preventing School Failure, 49(3), 5-10.

Dane, F. C. (2011). Evaluating research, methodology for 
people who need to read research. Los Angeles, CA: Sage.

Epanchin, B. C., \& Colucci, K. (2002). The professional development school without walls: A partnership between a university and two school districts. Remedial and Special Education, 23, 349-358.

Farooq, U., Schank, P., Harris, A., Fusco, J., \& Schlager, M. (2007). Sustaining a community computing infrastructure for online teacher professional development: A case study of designing tapped in. Computer Supported Cooperative Work, 16, 397-429.

Gall, M. D., Gall, J. P., \& Borg, W. R. (2007). Educational research. An introduction (8th ed.). Boston, MA: Allyn and Bacon.

Goo, M., Watt, S., Park, Y., \& Hosp, J. (2012). A guide to choosing Web-based curriculum-based measurement for the classroom. Teaching Exceptional Children, 45(2), 34-40.

Grossman, P., Wineburg, S., \& Woolworth, S. (2001). Toward a theory of teacher community. Teachers College Record, 103, 942-1012.

Hardman, E. L. (2011). Building professional learning communities in special education through social networking: Directions for future research. Journal on School Educational Technology, 7(2), 30-38.

Hardman, E. L. (2012). Supporting professional development in special education with Web-based professional learning communities: New possibilities with Web 2.0. Journal of Special Education Technology, 4(4), 17-31.

Hardman, E. L. (2014). Building a web-based community of practice. In M. D. Deprez (Ed.), Collaboration in education (Vol. 3, pp. 180-185). Stuyvesant Falls, NY: Rapid Intellect Group.

Hardman, E. L. (in press). Meeting the professional development needs of special educators in $21^{\text {st }}$ century classrooms. In M. D. Avgerinou \& S. Gialamas (Eds), Revolutionizing $k-12$ blended learning through the i2flex classroom model. Hershey, PA: IGI Global.

International Society for Technology in Education [ISTE]. (2007). The ISTE NETS and performance indicators for students (NETS•T). Retrieved from https://www.iste. org/standards/nets-for-students

International Society for Technology in Education [ISTE]. (2008). The ISTE NETS and performance indicators for teachers (NETS・T). Retrieved from https://www.iste. org/standards/nets-for-teachers

Jenkins, A. A., Pateman, B, \& Black, R. (2002). Partnerships for dual preparation in elementary, secondary, and special education programs. Remedial and Special Education, 21, 359-371.

Jones, M. L. (2009). A study of novice special educators' views of evidence-based practices. Teacher Education and Special Education, 32, 101-120.

Jones, S. R. (2012). Digital access. Using blogs to support adolescent writers with learning disabilities. Teaching Exceptional Children, 45(2), 16-23.
Klingner, J. K., Leftwich, S., van Garderen, D., \& Hernandez, C. (2004). Closing the gap: Enhancing student outcomes in an urban professional development school. Teacher Education and Special Education, 27, 292-306.

Kozleski, E., Mainzer, R., \& Deshler, D. (2000). Bright futures for exceptional learners. An agenda to achieve quality conditions for teaching and learning (ERIC Document Reproduction Service No. ED 451668). Reston, VA: Council for Exceptional Children.

Krathwohl, D. R. (2009). Methods of educational and social science research. The logic of methods. Long Grove, IL: Waveland Press.

Leedy, P. D., \& Ormrod, J. E. (2016). Practical research. Planning and design. Boston, MA: Pearson.

Leko, M. M., \& Brownell, M. T. (2009). Crafting quality professional development for special educators. What school leaders should know? Teaching Exceptional Children, 42(1), 64-70.

Little, M. E., \& King, L. M. (2008). Using online modules to bridge research to practice in classrooms. Teacher Education and Special Education, 32, 208-223.

Ludlow, B. (2012). Web 2.0 for teaching and learning. Teaching Exceptional Children, 45(2), 4.

McKenzi, R. G. (2009). A national survey of pre-service preparation for collaboration. Teacher Education in Special Education, 32, 379-393.

McLaughlin, M. W., \& Talbert, J. E. (2006). Building school based teacher learning communities. Professional strategies to improve student achievement. NY: Teachers College Press.

McLeskey, J., \& Billingsley, B. S. (2008). How does the quality and stability of the teaching force influence the research to practice gap. A perspective on the teacher shortage in special education. Remedial and Special Education, 20, 293-305.

McLeskey, J., \& Waldron, N. L. (2000). Inclusive schools in action. Making differences ordinary. Alexandria, VA: Association for Supervision and Curriculum Development.

National Council for the Accreditation of Teachers [NCATE]. (2008). Professional standards for the accreditation of teacher preparation institutions. Washington, DC: NCATE.

O'Shea, D. J., Hammitte, D. Mainzer, R., \& Crutchfield, M. D. (2000). From teacher preparation to continuing professional development. Teacher Education and Special Education, 23, 71-77.

Olthouse, J. M., \& Miller, M. T. (2012). Teaching talented writers with Web 2.0 tools. Teaching Exceptional Children, 45(2), 6-14.

Prater, M. A., \& Sileo. T. W. (2002). School and university partnerships in special education field experiences: A national descriptive study. Remedial and Special Education, 23, 325-355.

Prater, M. A., \& Sileo. T. W. (2004). Fieldwork requirements in special education preparation. A national 
study. Teacher Education and Special Education, 27, 251-263.

Rosenberg, M. A., O'Shea, L. J., \& O'Shea, D. J. (2006). Student teacher to master teacher. A practical guide for educating students with special needs. Upper Saddle River, NJ: Pearson.

Schlager, M. S., \& Fusco, J. (2003). Teacher professional development, technology, and communities of practice: Are we putting the cart before the horse? The Information Society, 19, 203-220.

Schrum, L. M., \& Levin, B. B. (2009). Leading $21^{\text {st }}$ century schools: Harnessing technology for engagement and achievement. Thousand Oaks, CA: Corwin Press.

Sindelar, P. T., Brownell, M. T., \& Billingsley, B. (2010). Special education teacher research: Current status and future directions. Teacher Education in Special Education, 33, 8-24.

Smith, T. M., \& Ingersoll, R. M. (2004). What are the effects of induction and mentoring on beginning teacher turnover? American Educational Research Journal, 41, 681.

University of Kansas Center for Research on Learning [UK-CRL]. (n.d.). Strategic instruction model (SIM). Retrieved from http://sim.kucrl.org

\section{About the Author}

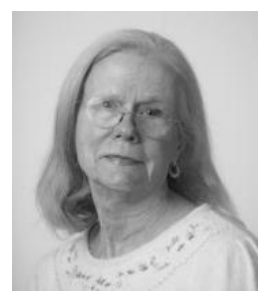

\section{Dr. Elizabeth Hardman}

Elizabeth Hardman is a member of the special education faculty at Northcentral University and holds degrees in special education from the University of Florida (Ph.D.), the University of Mississippi (M.Ed.), and the University of Arkansas (B.S.E.). She has taught in a wide variety of special education settings from prekindergarten to postsecondary and has developed two lines of research, one to study teacher participation in web-based professional learning communities and another to study the moral judgment of children with emotional and behavioral disorders and the effect anger has on its development. 